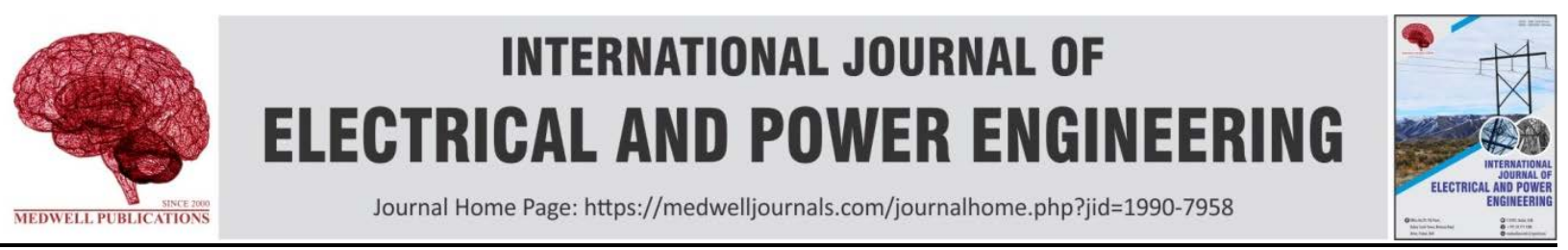

\title{
Application of Moment Method to Study of Charge Distribution, Stability in Circular and Square Conductors
}

\author{
${ }^{1}$ A. Faize, ${ }^{2}$ G. Alsharahi and ${ }^{2}$ A. Driouach \\ ${ }^{1}$ Department of Physics, Faculty Polydisciplinary, Mohammed 1st University, 62000 Nador, Morocco \\ ${ }^{2}$ Department of Physics, Faculty of Sciences, Abdelmalek Essaâdi University, 93000 Tetouan, Morocco
}

Key words: Numerical methods, electromagnetic, charge density, MoMs method, square conductors, rectangular

\section{Corresponding Author: \\ A. Faize \\ Department of Physics, Faculty Polydisciplinary, Mohammed 1st University, 62000 Nador, Morocco}

Page No.: 83-87

Volume: 13, Issue 06, 2019

ISSN: 1990-7958

International Journal of Electrical and Power Engineering

Copy Right: Medwell Publication
Abstract: Several numerical methods such as Method of moments, finite element method has been used in various fields. The moment method is used in electromagnetic and electricity and so on. This research consists of solving the uni-dimensional Poisson equation and calculating the surface charge density of a square plate brought to a potential by the moments method. Also, a detailed discussion and study of the Method of Moments (MoM) and briefly describing the theoretical basis for calculating the charge density $\sigma(\mathrm{x}, \mathrm{y})$ unknown on a metal plate maintained at a constant potential. For this, we wrote a numerical code in MATLAB based on the MoMs method that we applied to the study of load distribution, stability in circular and square conductors. The final results shows a charge distribution along the circular and rectangular conductor.

\section{INTRODUCTION}

In research literature a various methods has been used to solve the problem caused by complexity of electromagnetic field. The method of moments are used to solve the electromagnetic field problems. So with the development of technology in computer the computational electromagnetic and the moment method have followed closely behind.

Moreover, the use of the MOM moment method in electromagnetism has become popular, since, the research of Richmond in 1965 (Sadiku, 2000) and Harrington in 1967. This method has been successfully applied to a wide variety of electromagnetic problems of practical interest such as radiation due to thin elements such as wires and networks (Polycarpou, 2005), the diffusion of electromagnetic waves by dielectric bodies, magnetic and drivers, micro-ribbons analysis, propagation on a homogeneous land and radiation pattern of an antenna (LeVeque, 2002; Simons et al., 1991). In this research study a moment method is used to study the electromagnetic charge into different conductor. The square plate conductor are charged with length $L$ and the potential fixed at $1 \mathrm{~V}$. This conductor is subdivided into $\mathrm{N}$ square patches of side length $2 \mathrm{a}$ and area to $4 \mathrm{a}^{2}$ and assume the charge to be of constant value within each patch. We then choose (independent observation points, each at the center of a patch. In order to use this method, it is necessary to break down the studied structure into several parts or cells (De Doncker, 2003). As a result, the diffuser is replaced by a set of equivalent sources (current and charge density).

An adequate formulation of the integral equations allows to calculate the electric and magnetic fields (electric field methods of integral equation EFIE, Magnetic Field methods of Integral Equation MFIE). The obtained results shows the surface charge densities on the patches along the diagonal of the plate. As in the case of the thin wire, the electric charge accumulates near the corners and the edges of the plate and our solution could benefit from additional discretization density in those areas. 


\section{MATERIALS AND METHODS}

\section{Theoretical background}

One-dimensional cable by Poisson equation: The uni- dimensional Poisson equation can be writing Eq. 1 with $\varphi$ is the potential, described in the interval (Sadiku, 2000):

$$
\frac{\partial^{2} \varphi}{\partial x^{2}}=-x
$$

We are interesting to find $(x)$ that satisfied the boundary conditions for the potential as follow:

$$
\varphi(0)=\varphi(1)=0
$$

In one filed we resolve $\mathrm{l}(\varphi)=\mathrm{g}$ where $\mathrm{g}(\mathrm{x})=-\mathrm{x}$, this problem is easily solved by direct integration, one finds:

$$
\varphi(x)=\frac{1}{6} x-\frac{1}{6} x^{3}
$$

By the method of moments, we start with the choice of the basic functions $\varphi_{\mathrm{n}}$ as:

$$
\varphi_{\mathrm{n}}=\mathrm{x}-\mathrm{x}^{\mathrm{n}+1}
$$

with $\mathrm{n}=1,2,3, \ldots, \mathrm{N}$. It should be noted that these functions satisfy the boundary conditions and the solution is written in the following form:

$$
\varphi_{\mathrm{n}}=\sum_{\mathrm{n}=1}^{\mathrm{N}} \alpha_{\mathrm{n}}\left(\mathrm{x}-\mathrm{x}^{\mathrm{n}+1}\right)
$$

By choosing the weighting function that is the test function and using the following scalar product:

$$
\prec \varphi, g \succ=\int \varphi(x) g(x) d x
$$

The integrals are evaluated as follows:

$$
\begin{gathered}
\mathrm{l}_{\mathrm{mn}}=\prec \mathrm{w}_{\mathrm{m}}, l \varphi_{\mathrm{n}} \succ=\prec \mathrm{x}-\mathrm{x}^{\mathrm{m}+1} \frac{\partial^{2}}{\partial \mathrm{x}^{2}}\left(\mathrm{x}-\mathrm{x}^{\mathrm{n}+1}\right) \succ \\
\frac{\partial^{2}}{\partial \mathrm{x}^{2}}\left(\mathrm{x}-\mathrm{x}^{\mathrm{n}+1}\right)=\mathrm{n}(\mathrm{n}+1) \mathrm{x}^{\mathrm{n}-1} \\
\mathrm{l}_{\mathrm{mn}}=\int_{0}^{1}\left(\mathrm{x}-\mathrm{x}^{\mathrm{m}+1}\right) \mathrm{n}(\mathrm{n}+1) \mathrm{x}^{\mathrm{n}-1} \mathrm{dx} \\
\mathrm{l}_{\mathrm{mn}}=\prec \mathrm{w}_{\mathrm{m}}, \operatorname{l} \varphi_{\mathrm{n}} \succ=\frac{\mathrm{mn}}{\mathrm{m}+\mathrm{n}+1}
\end{gathered}
$$

And to calculate $g_{m}$ we use the following integral:
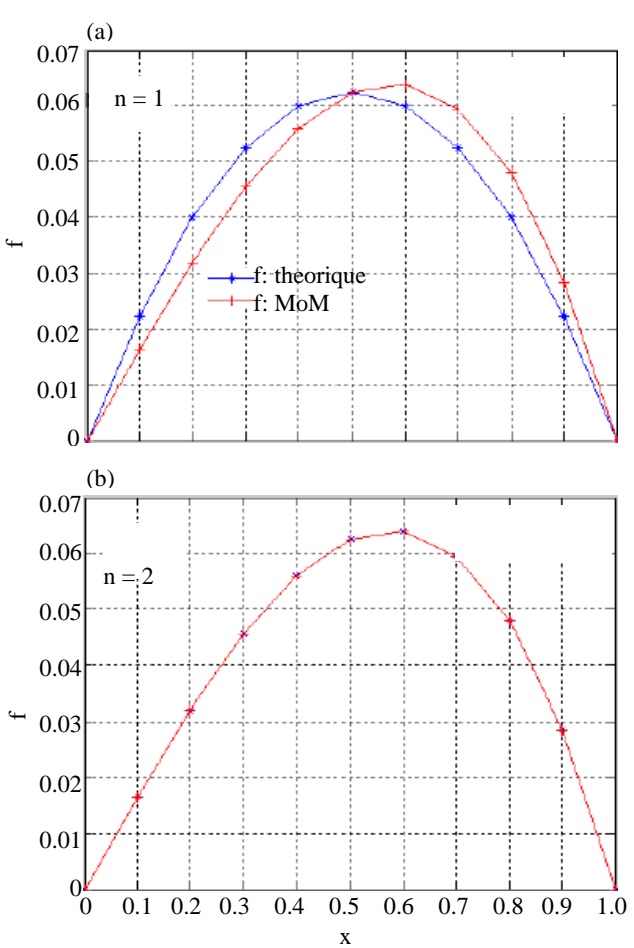

Fig. 1(a, b): The obtained results by the MOM compared to the theoretical results obtained by the exact solution

$$
\begin{aligned}
& g_{m}=\prec w_{n}, g \succ=\int_{0}^{1}\left(x-x^{m+1}\right)(x) d x \\
& g_{m}=\prec w_{n}, g \succ=\frac{m}{3(m+3)}
\end{aligned}
$$

We start with a single polynomial expression; this corresponds to the case where $n=1$, the use of Eq. 6 and 7 gives a single equation for:

$$
\left\{\frac{1}{3}\right\}\left\{\alpha_{1}\right\}=\left\{\frac{1}{12}\right\}
$$

The solution is $\alpha_{1}=1 / 4$ which leads to the solution:

$$
\varphi=\sum_{n=1}^{N} \alpha_{n} \varphi_{n}=\alpha\left(1-x^{2}\right)+\alpha\left(1-x^{3}\right)
$$

If we replace the values of Eq. 12 in the last equation, we obtain: The obtained results previously by MoM, for different values of $n$ are represented in the Fig. 1. These results are calculated via. a numerical code realized using MATLAB Software. From $n=2$ the results obtained by MoM coincide perfectly with those obtained theoretically (Exact solution) (Fig. 1). 


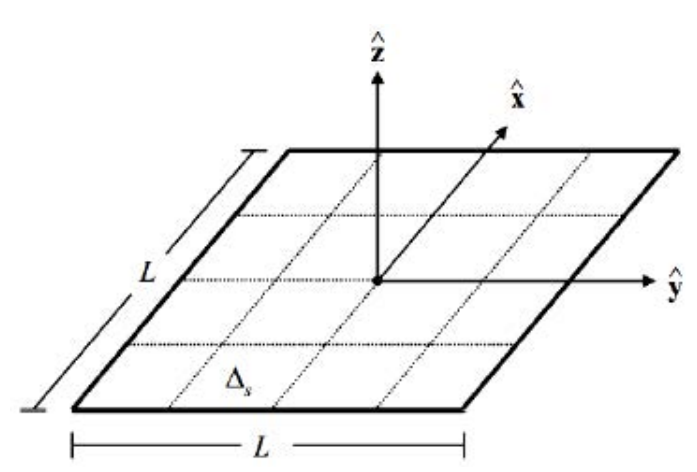

Fig. 2: Square conductive plate divided into a number $\mathrm{N} \times \mathrm{N} \Delta \mathrm{s}_{\mathrm{m}}$

Conductive plate loaded (square): The problem studied is to find the charge density $\sigma(\mathrm{x}, \mathrm{y})$ unknown on a metal plate maintained at a constant potential (Mishra et al., 2009). So, let consider a square conductive plate 2a Meters long and lying on the $\mathrm{z}=0$ plane with a center at the origin (Fig. 2). The potential on the plate is given by the integral (Gibson, 2008):

$$
\varnothing(\mathrm{x}, \mathrm{y}, \mathrm{z})=\int_{-\mathrm{a}}^{\mathrm{a}} \int_{-\mathrm{a}}^{-\mathrm{a}} \frac{\sigma\left(\mathrm{x}^{\prime}, \mathrm{y}^{\prime}\right)}{4 \pi \varepsilon \mathrm{R}} \mathrm{dx}^{\prime} d \mathrm{y}^{\prime}
$$

Where:

$$
\mathrm{R}=\sqrt{\left(\mathrm{x}-\mathrm{x}^{\prime}\right)^{2}+\left(\mathrm{y}-\mathrm{y}^{\prime}\right)^{2}}
$$

The condition at the limit is $\varnothing=\mathrm{V}$ (constant) on plate, the Eq. 10 becomes:

$$
\mathrm{V}=\int_{-\mathrm{a}}^{\mathrm{a}} \int_{-\mathrm{a}}^{\mathrm{a}} \frac{\sigma\left(\mathrm{x}^{\prime}, \mathrm{y}^{\prime}\right)}{4 \pi \varepsilon \sqrt{\left(\mathrm{x}-\mathrm{x}^{\prime}\right)^{2}+\left(\mathrm{y}-\mathrm{y}^{\prime}\right)^{2}}} \mathrm{dx} \mathrm{dy}^{\prime}
$$

where, $|\mathrm{x}|<\mathrm{a}$ and $|\mathrm{y}|<\mathrm{a}$ the important thing here is to determine the charge density of the plate. Its capacity is given by Harrington (1993):

$$
\mathrm{C}=\frac{\mathrm{q}}{\mathrm{V}}=\int_{-\mathrm{a}}^{\mathrm{a}} \int_{-\mathrm{a}}^{\mathrm{a}} \sigma(\mathrm{x}, \mathrm{y}) \mathrm{dxdy}
$$

The plate is subdivided into $\mathrm{N} * \mathrm{~N}$ square divisions of lateral length $2 \mathrm{~b}$ and area $\Delta \mathrm{s}_{\mathrm{n}}=4 \mathrm{~b}^{2}$ and we assume the constant charge in each division. We then choose $\mathrm{N}^{*} \mathrm{~N}$ observation points $\left(\mathrm{x}_{\mathrm{m}}, \mathrm{y}_{\mathrm{m}}\right)$ independent, each one is at the center of a division $\mathrm{m}=1,2,3, \ldots, \mathrm{N}$. The unknown charge density on the conductive surface develops as:

$$
\sigma(\mathrm{x}, \mathrm{y})=\sum_{\mathrm{n}=1}^{\mathrm{N}} \alpha_{\mathrm{n}} \varphi_{\mathrm{n}}
$$

With unknown coefficients $\alpha_{n}$ to be determined and $\varphi_{n}$ are basic functions known as:

$$
\varphi_{\mathrm{n}}= \begin{cases}1 & \text { on } \Delta S_{\mathrm{n}} \\ 0 & \text { elsewere }\end{cases}
$$

By replacing Eq. 17 in Eq. 15 and satisfying the resulting equation at the middle point $\left(\mathrm{x}_{\mathrm{m}}, \mathrm{y}_{\mathrm{m}}\right)$ of each of the elementary surfaces $\Delta s_{\mathrm{m}}$, we obtain the set of equations:

$$
\mathrm{V}=\sum_{\mathrm{n}=1}^{\mathrm{N}} 1_{\mathrm{mn}} \alpha_{\mathrm{n}} \mathrm{m}=1,2,3, \ldots, \mathrm{N}
$$

Where:

$$
\mathrm{l}_{\mathrm{mn}}=\int_{\Delta \mathrm{x}_{\mathrm{n}}} d \mathrm{x}^{\prime} \int_{\Delta \mathrm{y}_{\mathrm{n}}} d \mathrm{y}^{\prime} \frac{1}{4 \pi \varepsilon \sqrt{\left(\mathrm{x}_{\mathrm{m}}-\mathrm{x}^{\prime}\right)^{2}+\left(\mathrm{y}_{\mathrm{m}}-\mathrm{y}^{\prime}\right)^{2}}}
$$

$$
1_{\mathrm{mn}}=\int \Delta \mathrm{x}_{\mathrm{n}} \mathrm{dx}
$$

We take note that $l_{m n}$ is the potential at the center of $\Delta \mathrm{s}_{\mathrm{m}}$ for a uniform charge density and unit amplitude. A solution to the series (Eq. 19) gives the $\alpha_{n}$, who in their turns and by using Eq. 17, give the load densities on each element $\Delta \mathrm{S}_{\mathrm{m}}$. The corresponding capacity of the plate is calculated by (16) and given as:

$$
\mathrm{C}=\frac{1}{\mathrm{~V}} \sum_{\mathrm{n}=1}^{\mathrm{N}} \alpha_{\mathrm{n}} \Delta \mathrm{S}_{\mathrm{n}}=\sum_{\mathrm{mn}} \mathrm{l}_{\mathrm{mn}}{ }^{-1} \Delta \mathrm{S}_{\mathrm{n}}
$$

This result shows the capacity of an object is the sum of the capacities between each pair of subsections. To translate the above results into the language of the linear spaces and the method of moments, we proceed as follows:

$$
\begin{gathered}
\varphi(\mathrm{x}, \mathrm{y})=\sigma(\mathrm{x}, \mathrm{y}) \\
\mathrm{g}(\mathrm{x}, \mathrm{y})=\mathrm{V}|\mathrm{x}|<\mathrm{a} \text { and }|\mathrm{y}|<\mathrm{a} \\
\mathrm{l}(\varphi)=\int_{-\mathrm{a}}^{-\mathrm{a}} \int_{-\mathrm{a}}^{-\mathrm{a}} \frac{\varphi\left(\mathrm{x}^{\prime}, \mathrm{y}^{\prime}\right)}{4 \pi \varepsilon \sqrt{\left(\mathrm{x}-\mathrm{x}^{\prime}\right)^{2}+\left(\mathrm{y}-\mathrm{y}^{\prime}\right)^{2}}} \mathrm{dx^{ \prime }} d \mathrm{y}^{\prime}
\end{gathered}
$$

An appropriate scalar product is described in the following:

$$
\langle\varphi, \mathrm{g}\rangle=\int_{-\mathrm{a}}^{-\mathrm{a}} \int_{-\mathrm{a}}^{-\mathrm{a}} \varphi(\mathrm{x}, \mathrm{y}) \mathrm{g}(\mathrm{x}, \mathrm{y}) \mathrm{dxdy}
$$

To apply the method of moments, one uses the functions (18) and one defines the functions test (Renvoize, 2010):

$$
\mathrm{w}_{\mathrm{m}}=\delta\left(\mathrm{x}-\mathrm{x}_{\mathrm{m}}\right)-\delta\left(\mathrm{y}-\mathrm{y}_{\mathrm{m}}\right)
$$

Which is a two-dimensional Dirac function. The matrix of [g] is: 


$$
\left[\mathrm{g}_{\mathrm{m}}\right]=\left[\begin{array}{c}
\mathrm{V} \\
\mathrm{V} \\
\vdots \\
\mathrm{V}
\end{array}\right]
$$

The capacity (1.16) can be written as:

$$
\mathrm{C}=\frac{\langle\sigma, \varnothing>}{\mathrm{V}^{2}}
$$

As $\varnothing=\mathrm{V}$ on plate, Eq. 28 is the classical stationary formula for the capacity of a conductive body.

Evaluation of the matrix of elements: When the observation point coincides with the center of the considered element, we then have $\mathrm{m}=\mathrm{n}$, the integral in that case, presents a singularity and must be evaluated analytically. These elements of the matrix $(m=n)$ are the most dominant and are called auto-terms. The integral of self-term for the loaded plate is:

$$
I_{\mathrm{mn}}=\int_{-\mathrm{b}}^{\mathrm{b}} \int_{-\mathrm{b}}^{\mathrm{b}} \frac{1}{\sqrt{\left(\mathrm{x}^{\prime}\right)^{2}+\left(\mathrm{y}^{\prime}\right)^{2}}} d \mathrm{x}^{\prime} \mathrm{dy^{ \prime }}
$$

where, $l_{\mathrm{mn}}$ is the potential in the center of the element $\Delta \mathrm{s}_{\mathrm{m}}$ for a unit charge density. The first integration gives:
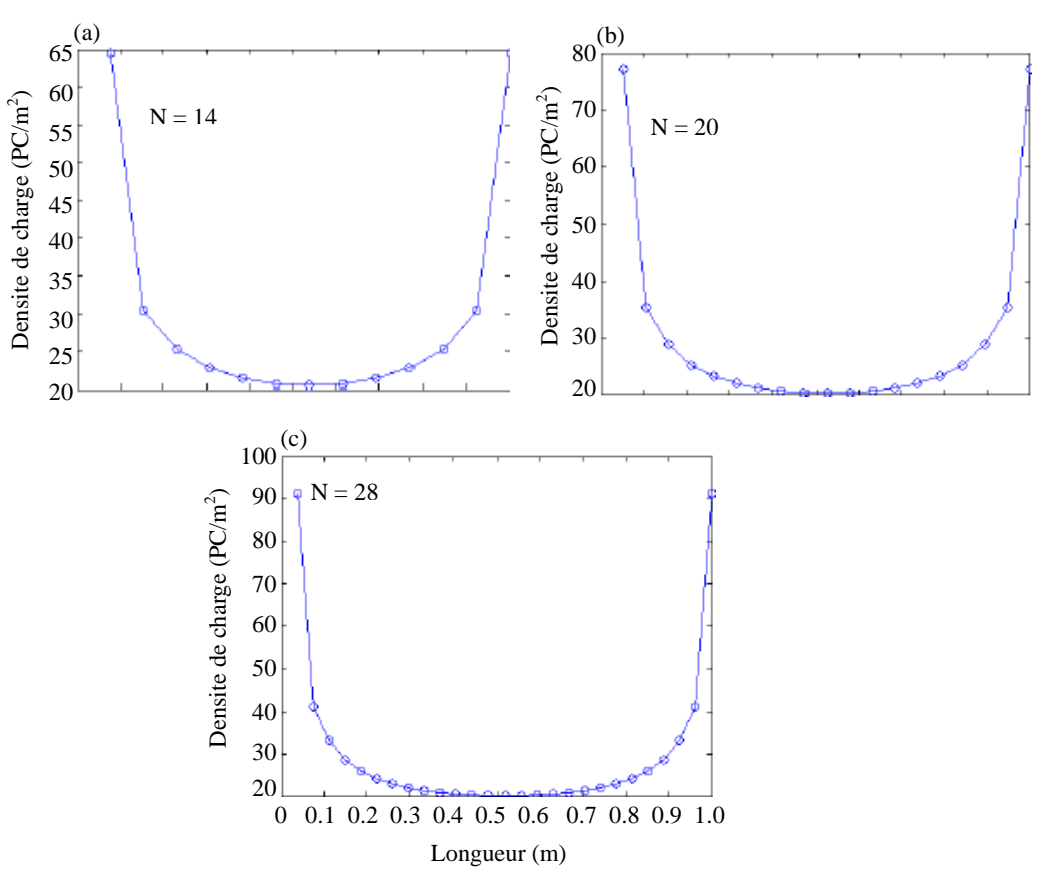

Fig. 3: Density of charge along the cells $\Delta \mathrm{s}_{\mathrm{m}}$, in the direction of the $\mathrm{x}$, located in the middle of the conductive square

plate. For $\mathrm{N}=14, \mathrm{~N}=20$ and $\mathrm{N}=28$

$$
\mathrm{l}_{\mathrm{mn}}=\int_{-\mathrm{b}}^{\mathrm{b}} \log \left[\frac{\sqrt{\mathrm{b}^{2}+\left(\mathrm{y}^{\prime}\right)^{2}}+\mathrm{b}}{\sqrt{\mathrm{b}^{2}+\left(\mathrm{y}^{\prime}\right)^{2}}-\mathrm{b}}\right] d y^{\prime}
$$

The second gives. Which reduces to (for $m=n$ ). For $\neq \mathrm{n}$, we use a simple approximation of the integral (1.29):

$$
\mathrm{l}_{\mathrm{mn}} \approx \frac{\Delta \mathrm{s}_{\mathrm{n}}}{4 \pi \varepsilon \mathrm{R}_{\mathrm{mn}}}=\frac{\mathrm{b}^{2}}{\pi \varepsilon \sqrt{\left(\mathrm{x}_{\mathrm{m}}-\mathrm{x}_{\mathrm{n}}\right)^{2}+\left(\mathrm{y}_{\mathrm{m}}-\mathrm{y}_{\mathrm{n}}\right)^{2}}}
$$

where, $x_{n}$ and $y_{n}$ or $\left(x_{m}\right.$ and $\left.y_{m}\right)$ are chosen to be at the center of the source cells.

\section{RESULTS AND DISCUSSION}

Recall that to study the density $\sigma(x, y)$ of the square plate by the MoM method, we divided the sides of it into $\mathrm{N}$ intervals, so, its surface will be divided into $\mathrm{N} \times \mathrm{N}$ elemental surfaces $\Delta S_{n}$. We represent here, as results, the charge densities of $N$ elements $\Delta S_{n}$, aligned in the direction of the $x$ (Fig. 3) and lying in the middle of the plate. As well, we made a representation of the results in three dimensions, giving the charge density as a function of $x$ and $y$ (Fig. 4). In these figures, the influence of the number $N$ of elements $\Delta S_{n}$ in the chosen model on the results obtained is perfectly noted. Let us also note, taking advantage of the results obtained for the charge density, that we have calculated the capacitance $\mathrm{C}$ of this plate. 


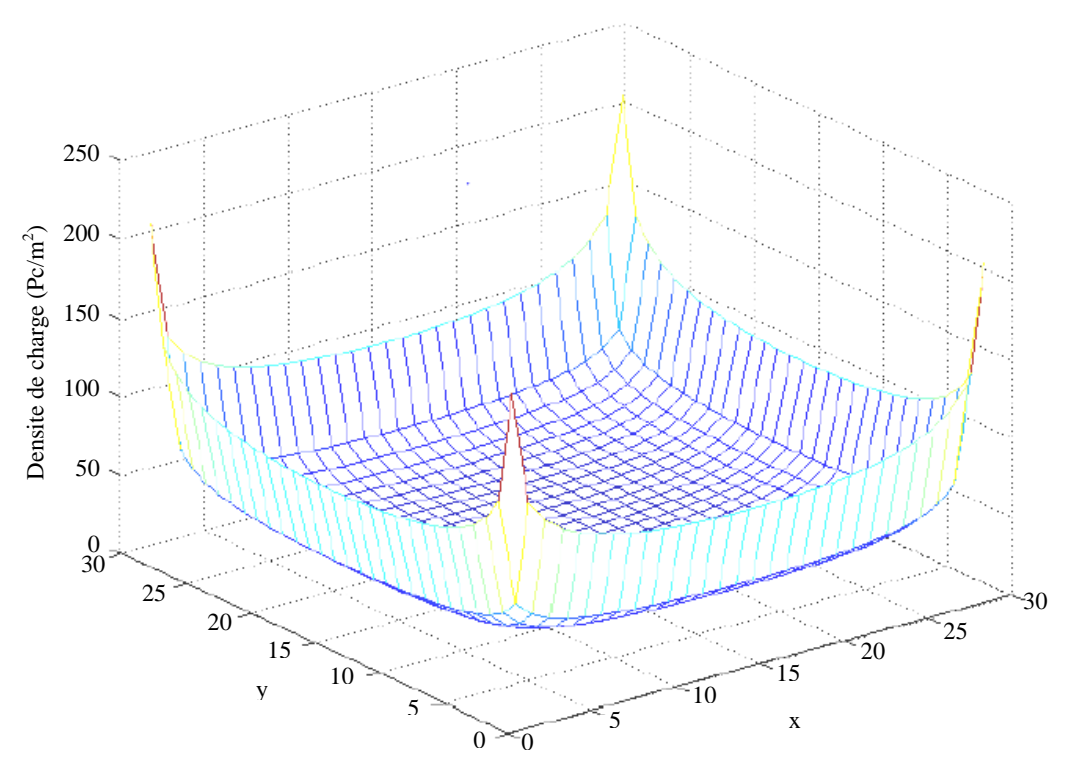

Fig. 4: Representation of the charge density $\sigma(x, y)$ of the conductive plate as a function of $x$ and $y$

\section{CONCLUSION}

The Method of Moments (MoM) is routinely used for the numerical solution of electromagnetic surface integral equations. This method is used to find the charge distribution in square plat conductor in it surface. So, this solution errors are inherent to any numerical computational method and error estimators $\mathrm{N}=14,20,28$ can be used to reduce these errors. The study conducted in this research is characterized by the use of numerical methods in two dimensions to find the charge density $\sigma$ (x, y) unknown on a metal plate maintained at a constant potential. We will study, in the first time, the Poisson equation and then we will expose in the second time to calculate the surface charge density of a square plate brought to a given potential. The obtained results shows the charge are distributed in the medium and be low in the board.

\section{REFERENCES}

De Doncker, P., 2003. A volume/surface potential formulation of the method of moments applied to electromagnetic scattering. Eng. Anal. Boundary Elem., 27: 325-331.

Gibson, W.C., 2008. The Method of Moments in Electromagnetics. Taylor \& Francis, Abingdon, England, UK., ISBN:9781420061451, Pages: 288.
Harrington, R.F., 1993. Field Computation by Moment Methods. IEEE Press, Piscataway, New Jersey, USA.

LeVeque, R.J., 2002. Finite Volume Methods for Hyperbolic Problems. Cambridge University Press, Cambridge, USA., ISBN: 9780521009249, Pages: 558.

Mishra, M., N. Gupta, A. Dubey and S. Shekhar, 2009. Application of quasi Monte Carlo integration technique in efficient capacitance computation. Prog. Electromagnet. Res., 90: 309-322.

Polycarpou, A.C., 2005. Introduction to the finite element method in electromagnetics. Synth. Lect. Comput. Electromagnet., Vol. 1, 10.2200/S00019ED1V01Y200604CEM004

Renvoize, V., 2010. Physique PC-PC*: Cours Complet Avec Tests, Corrected Exercises and Problems. Pearson, London, USA., ISBN: 9782744074417, Pages: 1052.

Sadiku, M.N.O., 2000. Numerical Techniques in Electromagnetics. CRC Press, NewYork, USA.

Simons, N.R.S., A.A. Sebak, E. Bridges and Y.M.M. Antar, 1991. Transmission-Line Matrix (TLM) method for scattering problems. Comput. Phys. Commun., 68: 197-212. 